\title{
HEALTH LOCUS OF CONTROL IN 12-YEARS-OLD SPORTING AND NON-SPORTING PUPILS
}

\author{
Milka Baryakova \\ National Sports Academy "Vassil Levski", Sofia, Bulgaria
}

\begin{abstract}
The benefits of active way of living and dealing with different sports activities interest scientific community more and more. The problem nowadays is quite topical as people start to have immobile way of living mainly due to the facilities given to them by the technical apparatuses. Serious problem in pupils starts to be the invasion of the computers and the games they offer in their daily life. Motor activity and sports occupations nowadays must be a priority in their life if they want to be healthy and successful. Science says that motivation in people for one or another activity depends on their health locus of control. Is this conclusion true in children too?

Purpose of our study was to find if inclusion in sports activities depend on the pupils' health locus of control.

Our study was carried through in October 2018 with 12-years-old pupils (boys and girls) from Bansko, school "Neofit Rilski". The number of the examined pupils was 81, distributed in control group of 49 (14 boys and 35 girls) nonsporting pupils of VI class and 32 sporting pupils (20 boys and 12 girls) of the same age and school. The health locus of control of pupils was defined using test adapted by Velichkov et al. (1987).

Our results show that in non-sporting pupils $46,94 \%(n=23)$ of them are with internal locus of control and $53,06 \%$ (n $=26)$ are with external locus of control. Quite similar are the results in the sporting pupils: 53,12\% ( $n=17)$ of them are with internal locos of control and $46,88 \%(n=15)$ with external locus of control. With $6,18 \%$ the internal locus of control is higher in the sporting pupils.
\end{abstract}

Key words: sporting pupils, non-sporting pupils, health locus of control

\section{INTRODUCTION}

The benefits of active way of living and dealing with different sports activities interest scientific community more and more. The problem nowadays is quite topical as people start to have immobile way of living mainly due to the facilities given to them by the technical apparatuses. Serious problem in pupils starts to be the invasion of the computers and the games they offer in their daily life. Motor activity and sports occupations nowadays have to be priority in their life if they want to be healthy and successful. Science says that motivation in people for one or another activity depends on their health locus of control. Is this conclusion true in children too?

Locus of control is an aspect of personality studies. The term locus of control is defined by Julian B. Rotter in 1966. The origin of the term is Latin and means "place" or "location". According to the author locus of control can be a source of reinforcement to motivate the behavior of the individual. J. $B$. Rotter defines locus of control as internal and external. The internal locus of control refers to people who seek motivation in themselves and rely on their capabilities. The external locus of control refers people who believe, that life is controlled and depends on outside factors, which the person can- not influence. J. B. Rotter creates a questionnaire to measure locus of control in 23-item and it is most widely used. This is not the only questionnaire. In 1961, Bailer designs 23-item scale for children. Follow Crandall in 1965, etc. Many measures of locus of control have appeared since Rotter's scale, and lot of studies are carried out in world scale since that time.

Some studies show that with age people develop a more external locus of control (Hovenkamp-Hermelink, et al. 2019). Other study results are ambiguous. Longitudinal data collected by Gratz and Karel imply that internality may increase until middle age, decreasing thereafter. Age plays an important role in one's internal and external locus of control. When comparing a young child and an older adult on the base of their levels of locus of control, the older person will have more control over the attitude and approach to the situation. With increasing of age people become aware of the fact that events outside of their own control happen, and that other individuals can have control on their health and life outcomes (Jacobs-Lawson, et al., 2011)

All Rotter's followers continue to explore the impact of the locus of control over achievement, learning processes, political beliefs, illness responses, health 
information seeking, self-confidence.

Studies in Bulgaria show that "People with an internal locus of control have better somatic and mental health compared to those with an external locus of control - the former has lower blood pressure, suffer less of heart attacks, they are less depressed and anxious, and - they also easily deal with stress. People with an internal locus of control tend to have higher self-esteem, they have more social skills, more confidence, and more success at school and at work are" (Kotseva, Baltadzhieva, 2016)

There are also other studies in the Bulgarian psychological literature on locus of control in students in an academic environment, study on the influence of the locus of control in selecting approaches to motivate staff, determining the locus of control in perennials, the relationship between the health locus of control and coping with anxiety and stress, etc. Still there is not enough information about the locus of control among adolescent pupils.

\section{METHODS}

We applied this study to this target age group 12-years-old pupils.

The study was carried through in October 2018 with 12 -years-old pupils (boys and girls) from Bansko, school "Neofit Rilski".The number of the examined pupils was 81, distributed in control group of 49 (14 boys and 35 girls) non-sporting pupils of VI class and 32 sporting pupils ( 20 boys and 12 girls) of the same age and school. The health locus of control of pupils was defined using test adapted by Velichkov, et al. (1987) for the Bulgarian children.

The questionnaire contains pairs of statements marked with the letter's "A" and "B". All 20 questions have to get an answer with one of the given statements. There are not wrong statements. The determination of the localization of the control is as follows: one part of the statements carries 1 point, and other 0 points. The answers bearing 1 point are $2 \mathrm{a}, 3 \mathrm{~b}, 4 \mathrm{~b}, 6 \mathrm{~b}, 7 \mathrm{a}, 8 \mathrm{a}, 10 \mathrm{~b}, 11 \mathrm{~b}, 12 \mathrm{a}, 14 \mathrm{a}, 15 \mathrm{a}, 16 \mathrm{~b}$, $18 \mathrm{~b}, 19 \mathrm{a}, 20 \mathrm{a}$. A score of up to 7 points refers for children with internal locus of control. From 8 or more points is considered as an external locus of control.

\section{RESULTS}

Our assumption was that in sporting pupils will prevail the number of pupils with internal locus of control. The gathered data show that in non-sporting pupils $46,94 \%(\mathrm{n}=23)$ of them are with internal locus of control and 53,06\% $(n=26)$ are with external locus of control (Figure 1). Quite similar are the results in the sporting pupils: $53,12 \%(\mathrm{n}=$ 17) of them are with internal locos of control and $46,88 \%(n=15)$ with external locus of control. With $6,18 \%$ the internal locus of control is higher in the sporting pupils.

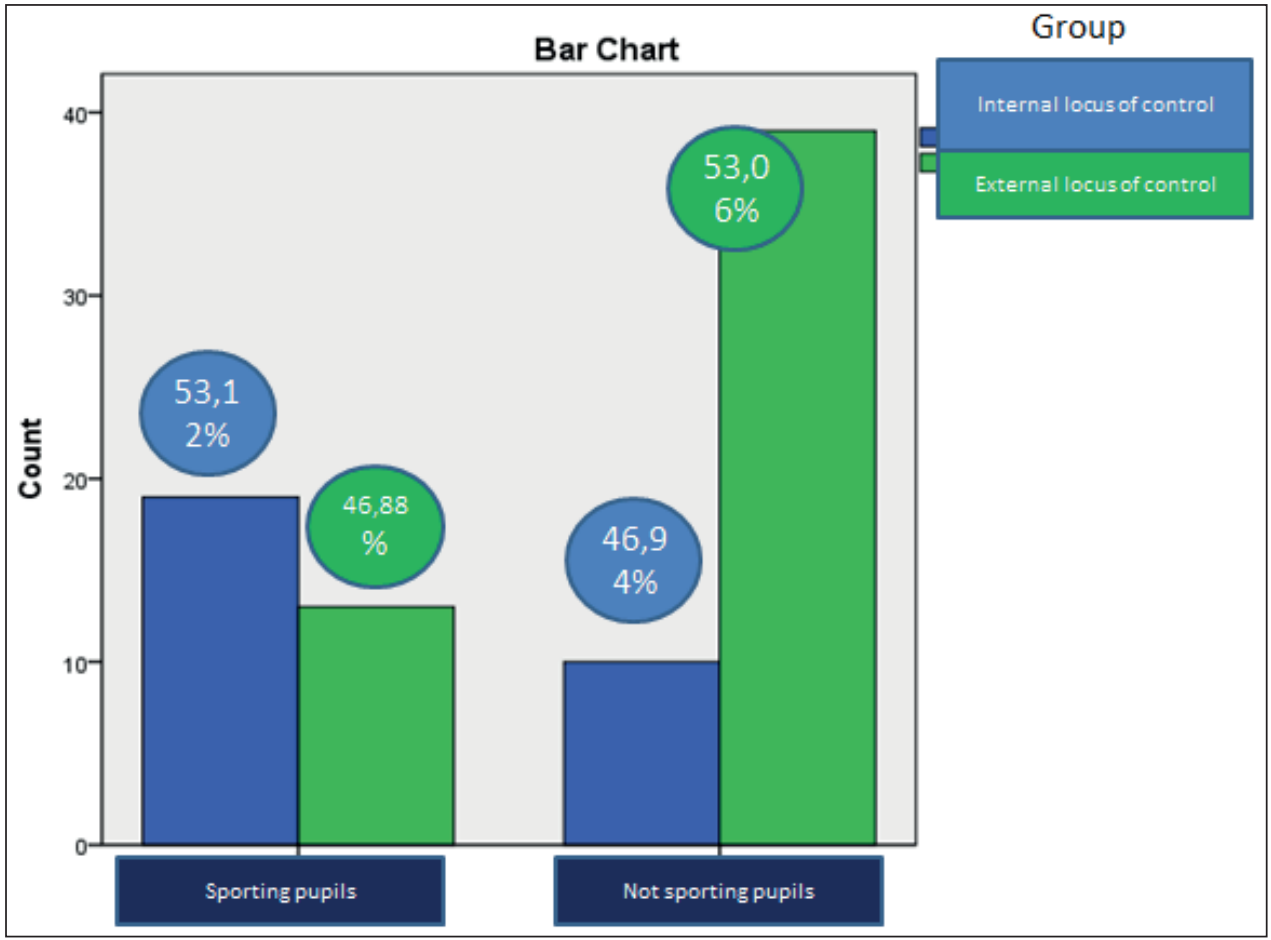

Figure 1. Internal locus of control and external locus of control Percentage in 12-years-old sporting and non-sporting pupils 
The data show also that $52,94 \%(n=18)$ of the boys are with an internal locus of control, and 47, 06\% (n $=16$ ) of them are with an external locus of control. Girls are with slightly less percent of internal locus of control $-46,81 \%(n=22)$ than boys. In girls prevail the external locus of control $-53,19 \%(n=25)$.

\section{CONCLUSIONS AND DISCUSSION}

In regard with the sexual differences in our study we found that in 12-years-old boys prevail the internal locus of control. Boys rely more on themselves even at this age. In 12-years-old girls prevail the external locus of control.

Having in mind the fact if pupils are engaged in some sport activity or not, we found that in sporting 12-years-old pupils prevail the internal locus of control. As the difference in percentage in sporting and non-sporting pupils is not so great $(6,18 \%)$ we made the conclusion that kind of locus of control is not a determinative factor for the inclusion of $\mathrm{pu}$ pils in sports activities.

\section{REFERENCES}

Rotter, Julian B (1966). Generalized expectancies for internal versus external control of reinforcement. Psychological Monographs: General and Applied. 80: 1-28.
Hovenkamp-Hermelink, J.H.M., Jeronimus, B.F., Spinhoven, P., Penninx, B.W., Schoevers, R.A., Riese, H. (2019). Differential associations of locus of control with anxiety, depression and life-events: A five-wave, nineyear study to test stability and change. Journal of Affective Disorders. 253 (1): pp. 26-34.

Jacobs-Lawson, Joy M; Waddell, Erin L; Webb, Alicia K (2011). Predictors of Health Locus of Control in Older Adults. Current Psychology. 30 (2): 173-183.

Kotseva, T.I., Baltadzhieva, JS. (2016). Dimensions of Personal Self-Control in Adolescents and Students, Jubilee Scientific Conference with International Participation $-2016$.

Velichkov, A., Lukarski, G., Radoslavova, M., Ruseva, L., Genova, S. (1987). Method for measuring the localization of the control: design, stability - validity. Psychological Research, 96-106.

\section{Corresponding author:} Milka Baryakova

Department Theory and Methodics of Physical Education National Sports Academy "Vassil Levski" Sofia, 1700, Bulgaria E-mail: milka.baryakova@gmail.com 